\title{
Produção de hidrogênio em reator anaeróbio de fluxo contínuo utilizando glicerol bruto oriundo da produção de biodiesel
}

\author{
Hydrogen production in anaerobic continuous \\ flow reactor using crude glycerol from biodiesel production
}

\author{
Luan Vieira Adames ${ }^{1,2}$, Lorena Oliveira Pires ${ }^{1}$, \\ Maria Ângela Tallarico Adorno ${ }^{3}$, Sandra Imaculada Maintinguer ${ }^{2,4}$
}

\footnotetext{
${ }^{1}$ Instituto de Química/UNESP, Rua Prof. Francisco Degni, n. 55, Araraquara, SP, CEP: 14.800-900, Brasil.

${ }^{2}$ IPBEN/UNESP, Rua 10, n. 2527, Rio Claro, SP, CEP: 13.500-230, Brasil.

${ }^{3}$ Universidade de São Paulo, USP, Laboratório de Processos Biológicos - LPB, Av. João Dagnone, 1100, Jd. Santa Angelina), São Carlos, SP, CEP: 13.563-120, Brasil.

${ }^{4}$ Universidade de Araraquara, Uniara - Programa de Pós-Graduação em Desenvolvimento Territorial e Meio Ambiente, Rua Carlos Gomes, 1338, Centro, Araraquara, SP, CEP: 14801-340, Brasil.

e-mail: lvadames@gmail.com, Sandra.i.maintinguer@unesp.br
}

\section{RESUMO}

O esgotamento das reservas de petróleo e a crescente preocupação com as mudanças climáticas têm acelerado novas pesquisas para obtenção de energias renováveis. A produção de biogás através da digestão anaeróbia vem se mostrando uma ótima opção, não só para produção de energia, como também para manejo adequado de resíduos orgânicos. O biodiesel teve sua produção aumentada em diversos países por ser um combustível renovável e biodegradável. Entretanto, é largamente obtido da transesterificação de óleos vegetais e animais, onde seu rendimento é 9 litros de biodiesel para 1 litro de glicerol. O glicerol bruto possui grau reduzido de pureza, se tornando uma matéria-prima barata com potencial para produção de energia renovável, principalmente gás hidrogênio $\left(\mathrm{H}_{2}\right)$ e metano $\left(\mathrm{CH}_{4}\right)$. Nesse sentido, os objetivos deste estudo foram: operar um reator horizontal de leito fixo (RAHLF), com alimentação contínua e determinar a partida do mesmo na produção de $\mathrm{H}_{2}$ a partir de glicerol bruto residual de biodiesel, co-digerido em esgoto sanitário nas fases de: partida, ensaio 1 e ensaio 2. Durante a fase de partida e Ensaio 1, o afluente foi constituído de 99\% esgoto $1 \%$ glicerol bruto (v/v) e 1,5\% de glicerol bruto no Ensaio 2. Na partida e ensaio 1 foram verificadas médias de produção de $1 \mathrm{~mol} \mathrm{H}_{2} \mathrm{~m}^{3} \mathrm{~d}^{-1}$ e $3,2 \mathrm{mols} \mathrm{H}_{2} \mathrm{~m}^{3} \mathrm{~d}^{-1}$, respectivamente. A maior produção diária atingida foi 11,34 mols $\mathrm{H}_{2} \mathrm{~m}^{3} \mathrm{~d}^{-1}$ no Ensaio 2 com geração média de ácidos graxos voláteis (AGV) de $3414,0 \mathrm{mg} \mathrm{L}^{-1}$ Tais resultados foram promissores e novos avanços com proporções mais elevadas do glicerol bruto e agentes tamponantes poderão evitar grandes variações de $\mathrm{pH}$, viabilizando assim gerações mais elevadas e mais estáveis de $\mathrm{H}_{2}$, em reatores contínuos.

Palavras-chave: Biogás. Esgoto Sanitário. Reator Contínuo.

\section{ABSTRACT}

The depletion of oil reserves and the growing concern about climate change have accelerated new research to obtain renewable energy. The production of biogas through anaerobic digestion has proved to be a great option, not only for energy production, but also for the proper management of organic waste. Biodiesel had its production increased in several countries as it is a renewable and biodegradable fuel; moreover, it does not require major modifications for its use in diesel engines. However, it is largely obtained from the transesterification of vegetable oils and animal fat, where its yield is 9 volumes of biodiesel to 1 volume of glycerol. The crude glycerol has a low degree of purity, becoming an inexpensive raw material with the potential to produce renewable energy, mainly hydrogen gas $\left(\mathrm{H}_{2}\right)$ and methane $\left(\mathrm{CH}_{4}\right)$. In this sense, the objectives of this 
study were: to operate a horizontal anaerobic reactor with fixed bed (HARFB), with continuous feeding and to determine its start in the production of $\mathrm{H}_{2}$ from residual biodiesel glycerol co-digested in sanitary sewage in the phases from: Startup, Test 1 and Test 2. During the Startup and Test 1 assay, the affluent was constituted by $99 \%$ sewage $1 \%$ crude glycerol (v/v) and $1.5 \%$ crude glycerol in Test 2 . At Startup and Test 1 , production averages of $1 \mathrm{~mol} \mathrm{H}_{2} \mathrm{~m}^{3} \mathrm{~d}^{-1}$ and 3.2 moles $\mathrm{H}^{2} \mathrm{~m}^{3} \mathrm{~d}^{-1}$ were verified, respectively. The highest daily production achieved was 11.34 moles $\mathrm{H}_{2} \mathrm{~m}^{3} \mathrm{~d}^{-1}$ in Test 2 with an average generation of volatile fatty acids (VFA) of $3414.0 \mathrm{mg} \mathrm{L}^{-1}$. Such results were promising and new advances with higher proportions of crude glycerol and buffering agents could avoid large $\mathrm{pH}$ variations, thus enabling higher and more stable generations of $\mathrm{H}_{2}$ in continuous reactors.

Keywords: Biogas. Sanitary sewage. Continuous Reactor.

\section{INTRODUÇÃO}

O Brasil está entre os maiores produtores e consumidores de biodiesel, com uma capacidade de produção de mais de 8500 milhões de litros [1]. Cada tonelada de biodiesel produzido gera aproximadamente $100 \mathrm{~kg}$ de glicerol bruto; principal coproduto da sua produção. No entanto, a quantidade de glicerol bruto gerado na produção de biodiesel pode variar, dependendo das condições de operação das plantas de transesterificação [2].

O glicerol bruto é obtido a partir da produção de biodiesel, que usualmente ocorre pela transesterificação de óleos vegetais e/ou animais. Além disso, o glicerol em sua forma bruta contém várias impurezas, tais como álcoois, ácidos graxos, ésteres, sabões e metais pesados [3] . Apesar das amplas aplicações de glicerol puro na indústria farmacêutica, alimentar e cosmética, a sua purificação gera custo, especialmente para os pequenos e médios produtores de biodiesel, pois a ampla demanda de glicerol fez o custo de venda baixar nos últimos anos $[\underline{4}, \underline{5}]$. Nesse sentido, alternativas de manejo do glicerol bruto tem sido estudada tais como combustão, compostagem, inserção na alimentação animal, conversão térmica e biológica [6-8].

Dentre as alternativas de manejo, a biodigestão do glicerol tem como vantagem a conversão da matéria orgânica à hidrogênio e metano que podem ser utilizados como biocombustíveis [3, 9 ]. Para melhorar estas taxas de conversão, vem se estudando o emprego de sua co-digestão com outros resíduos como lodo de esgoto, resíduos da suinocultura, resíduos vegetais e água residuária de cervejaria [9-12].

A co-digestão anaeróbia é a utilização combinada de dois ou mais tipos diferentes de resíduos. Tal abordagem vem sendo utilizada para aumentar a capacidade de tamponamento dos reatores anaeróbios e assim diluir compostos químicos potencialmente tóxicos [13]. Além disso, tal estratégia pode suprir a deficiência de nutrientes requeridos pelos micro-organismos anaeróbios [14] e, consequentemente, melhorar a produção de biogás a partir de resíduos orgânicos como o glicerol.

A utilização de esgotos sanitários, em virtude da disponibilidade de grandes volumes e da proximidade dos grandes centros consumidores, é uma proposta viável para a co-digestão. De acordo com PEDROZA et al. [15], a produção de esgoto doméstico por habitante no Brasil gira em torno de 80 a 200 litros por dia. Segundo pesquisa do Instituto Trata Brasil [16] apenas 40\% do esgoto doméstico gerado no Brasil é tratado. Além disso, a média de esgoto tratado nas 100 maiores cidades brasileiras foi de $40,93 \%$ e somente as capitais do país lançaram 1,2 bilhão de $\mathrm{m}^{3}$ de esgotos na natureza em 2013. O uso de reatores anaeróbios para o tratamento de esgotos sanitários é viável para a remoção de matéria orgânica, mas pouco estudado para produção energética de biogás, em virtude da baixa carga orgânica deste efluente $[\underline{17}, \underline{18}]$. A co-digestão anaeróbia do esgoto sanitário com o glicerol bruto pode proporcionar o aumento da produção de biogás e, consequentemente, de energia.

A configuração dos reatores é parte crucial para o sucesso da digestão anaeróbia, bem como as condições operacionais (carga orgânica volumétrica, alcalinidade, $\mathrm{pH}$, composição do substrato) [19]. O foco dos estudos da produção biológica de $\mathrm{H}_{2}$ são reatores operados em regime de batelada. Entretanto, reatores anaeróbios horizontais de leito fixo (RAHLF) têm sido aplicados com sucesso na co-digestão de resíduos vegetais e águas residuárias de suinocultura [20]. Nenhum estudo foi realizado com o glicerol bruto nessa configuração de reatores, que pode contribuir para consumo de maiores cargas orgânicas de glicerol, uma vez que uma quantidade mais elevada de microrganismos fica aderida ao meio suporte.

Alcançar condições propicias para uma produção biológica contínua de $\mathrm{H}_{2}$ a partir do glicerol bruto gerado na produção do biodiesel seria um grande avanço para área de biocombustíveis, beneficiando também questões ambientais. Nesse sentido, o objetivo desse estudo foi preencher esta lacuna, realizando o estudo da produção de $\mathrm{H}_{2}$ em um reator anaeróbio horizontal de leito fixo (RAHLF), alimentado continuamente com glicerol bruto, advindo da produção do biodiesel, co-digerido com esgoto sanitário, em diferentes proporções. 


\section{MATERIAIS E MÉTODOS}

\subsection{Constituição do afluente}

Glicerol bruto foi a principal fonte de matéria orgânica, co-digerido com esgoto sanitário bruto, em diferentes proporções durante os ensaios, conforme descrito a seguir.

\subsubsection{Glicerol bruto}

O glicerol bruto foi obtido a partir de transesterificação de óleos vegetais e sebo animal, cedido por empresa de purificação de glicerol (Brotas - SP). O glicerol (Tabela 1) e armazenado em galões polietileno escuro e mantidos em temperatura ambiente até sua utilização.

Tabela 1. Caracterização do glicerol bruto

\begin{tabular}{c|c|c}
\hline PARÂMETRO & RESULTADO & METODOLOGIA \\
\hline DQO $\left(\mathrm{kg} \mathrm{L}^{-1}\right)$ & 1,92 & APHA 3113-B \\
\hline Densidade $\left(\mathrm{g} \mathrm{cm}^{-3}-25^{\circ} \mathrm{C}\right)$ & 1,241 & ASTM D4052 \\
\hline Umidade $(\%)$ & 11,41 & ASTM E203 \\
\hline Cloretos $(\%)$ & 5,30 & Mohr \\
\hline Glicerol $(\%)$ & 80,63 & Titulométrico \\
\hline Cinzas $(\%)$ & 5,11 & ASTM D874 \\
\hline MONG $(\%)$ & 2,84 & ISSO - 2464 \\
\hline $\mathrm{pH}$ & 4,35 & Potênciométrico
\end{tabular}

DQO: demanda química de oxigênio; MONG: Matéria orgânica não glicerol.

\subsubsection{Esgoto sanitário}

O esgoto foi concedido pela empresa BRK Ambiental, responsável pela estação de tratamento de esgotos do município de Rio Claro - SP; foi coletado após sua passagem pelo tratamento preliminar (caixa de areia + gradeamento), com DQO (demanda química de oxigênio) média de $350 \mathrm{mg} \mathrm{L}^{-1}$, sólidos totais de $150 \mathrm{mg} \mathrm{L}^{-1}$ e pH 7,0. Sua foi realizada semanalmente e foi armazenado em galões de polietileno escuro, mantido em temperatura ambiente.

\subsubsection{Tamponamento}

Foi adicionado ao afluente bicarbonato de sódio $\left(\mathrm{NaHCO}_{3}\right)$ durante o ensaio $1\left(1 \mathrm{~g} \mathrm{~L}^{-1}\right)$ e ensaio $2\left(3 \mathrm{~g} \mathrm{~L}^{-1}\right)$ para a manutenção da faixa de $\mathrm{pH}$ adequada para os microrganismos, além de evitar alterações com a aplicação de elevadas cargas orgânicas volumétricas (COV).

\subsection{Fonte de inóculo}

Lodo granular metanogênico de um reator UASB (Upflow Anaerobic Sludge Blanket) utilizado para o tratamento de resíduos do abate de aves, foi cedido pela avícola Dacar (Tiete - SP), denominado inoculo in natura. Com objetivo de inativar os microrganismos metanogênicos, os quais consomem gás hidrogênio para produção de metano, foi realizado o pré-tratamento ácido [21], denominado inoculo pré-tratado. O lodo anaeróbio foi inserido em frascos Duran $(2 \mathrm{~L})$ contendo $1 \mathrm{~L}$ de volume reacional preenchido com meio de cultivo (Extrato de levedura $10 \mathrm{~g} \mathrm{~L}^{-1}$, Peptona $10 \mathrm{~g} \mathrm{~L}^{-1}$, Glicerina $5 \mathrm{~g} \mathrm{~L}^{-1}$ ) sob pH 3,0, mantido por 24 h e a $37^{\circ} \mathrm{C}$. Após esse período o $\mathrm{pH}$ do lodo foi ajustado em 5,5 e inserido no reator junto com o meio suporte.

\subsection{Parâmetros operacionais do Reator Anaeróbio Horizontal de Leito Fixo (RAHLF)}

O RAHLF foi instalado na parte externa do Instituto de Pesquisa em Bioenergia (IPBEN), Rio Claro - SP. Foi confeccionado com cano de PVC, possuindo 3 saídas superiores interconectadas para a coleta de biogás, 3 saídas laterais para coleta de efluentes, pontos de amostragem na entrada e saída, e 3 pontos de coleta localizados na parte inferior do reator, para coleta da biomassa microbiana (lodo anaeróbio). O reator tubular possuía 2 metros de comprimento e $5 \mathrm{~cm}$ de diâmetro, preenchido com meio suporte (eletroduto corrugado cortado em anéis de $2 \mathrm{~cm}$ de comprimento e $2 \mathrm{~cm}$ de diâmetro), resultando em um volume útil do reator de 3,8 


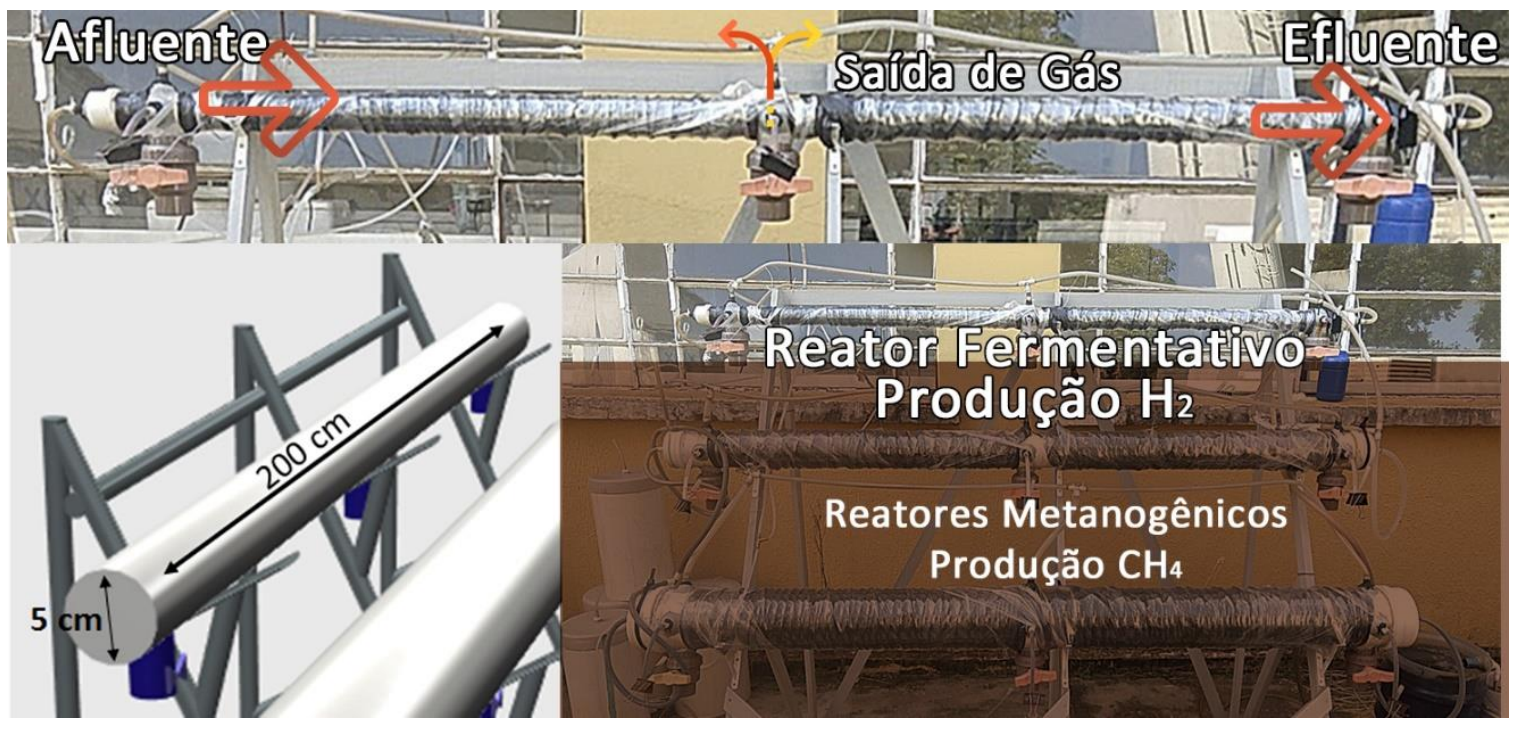

Figura 1: Reator Anaeróbio Horizontal de Leito Fixo (RAHLF)

O reator foi mantido com sistema auxiliar de controle de temperatura, que consistia em mangueiras de silicone enroladas por todo a sua extensão, onde a água aquecida em um banho maria $\left(37^{\circ} \mathrm{C}\right)$ era recirculada de acordo com a temperatura do termostato acoplado na superfície do reator.

$\mathrm{Na}$ fase de partida do reator a alimentação foi realizada apenas com esgoto bruto, em velocidade de $6,33 \mathrm{ml}$ $\min ^{-1}$ por 20 dias. Após a partida foi adicionado $1 \%(\mathrm{v} / \mathrm{v})$ de glicerol bruto ao afluente por um período de operação de 200 dias. Nos experimentos seguintes (ensaios 1 e 2) a velocidade do afluente foi reduzida para 2,64 $\mathrm{mL} \mathrm{min}^{-1}$, o que proporcionou aumento no tempo de detenção hidráulica (TDH) de 10h para 24h. Os ensaios foram operados até a estabilidade nos resultados das análises no efluente e biogás. Durante os ensaios 1 e 2 o afluente foi mantido refrigerado a $4^{\circ} \mathrm{C}$ e bombeado diretamente para o reator.

Os parâmetros operacionais dos reatores nas fases de partida, ensaio 1 e ensaio 2 estão especificados na Tabela 2 .

Tabela 2: Parâmetros operacionais e características físico-químicas do afluente

\begin{tabular}{l|c|c|c|c|c|c|c}
\hline & $\begin{array}{c}\text { DURAÇÃo } \\
(\text { dias })\end{array}$ & $\begin{array}{c}\text { COMPOSIÇÃO } \\
\text { DO AFLUENTE } \\
(\mathrm{v} / \mathrm{v})\end{array}$ & $\begin{array}{c}\text { COV } \\
\left(\mathrm{g} \mathrm{DQO} \mathrm{d}^{-1}\right)\end{array}$ & $\begin{array}{c}\text { DQO } \\
\left(\mathrm{g} \mathrm{L}^{-1}\right)\end{array}$ & $\mathbf{p H}$ & $\begin{array}{c}\text { Adição de } \\
\mathrm{NaHCO}_{3} \\
\left(\mathrm{~g} \mathrm{~L}^{-1}\right)\end{array}$ & $\begin{array}{c}\text { TDH } \\
(\text { horas })\end{array}$ \\
\hline Partida & 200 & $\begin{array}{c}1 \% \text { Glicerol } \\
99 \% \text { Esgoto }\end{array}$ & 99,1 & 10,6 & 6,34 & - & 10 \\
\hline Ensaio 1 & 66 & $\begin{array}{l}1 \% \text { Glicerol } \\
99 \% \text { Esgoto }\end{array}$ & 51,1 & 13,0 & 7,18 & 1 & 24 \\
\hline Ensaio 2 & 106 & $\begin{array}{l}1,5 \% \text { Glicerol } \\
98,5 \% \text { Esgoto }\end{array}$ & 69,8 & 17,9 & 7,41 & 3 & 24 \\
\hline
\end{tabular}

\subsection{Analises físico-químicas e microbiológicas}

$\mathrm{O}$ afluente e efluente do reator foi monitorado mediante análises físico-químicas semanais de: $\mathrm{pH}$ [22], alcalinidade [23], ácido graxos voláteis (AGV) [24], demanda química de oxigênio (DQO) [22] .

A quantificação de culturas anaeróbias geradoras de $\mathrm{H}_{2}$ foi realizada com o inóculo in natura (sem prétratamento) e no inoculo pré-tratado ao final da operação do ensaio 1, com 266 dias de operação por técnica de plaqueamento Pour Plate [25]. O inoculo pré-tratado do ensaio 1 foi coletado nos 3 registros da parte 
inferior do reator (Figura1) e misturado em partes iguais para a obtenção de amostra composta do reator.

\subsection{Quantificação do Biogás}

O método de deslocamento de água foi utilizado para as medidas da produção de biogás [26]. A leitura da produção foi automatizada com o deslocamento da água em tubos em "U" e registro em tempo real através de sensores ligado a um microprocessador Arduino, adaptado de [27].

$\mathrm{O}$ teor de hidrogênio no biogás foi determinado semanalmente por cromatografia em fase gasosa em um cromatógrafo Shimadzu GC-2014, equipado com um Coluna Carboxen 1010 PLOT (30 m de comprimento 0,53 mm diâmetro), equipado com detector de condutividade térmica (TCD), e argônio como gás de arraste. As temperaturas do injetor e do detector foram de $220^{\circ} \mathrm{C}$ e $230^{\circ} \mathrm{C}$, respectivamente. O programa com rampa de temperaturas da coluna foi de $120^{\circ} \mathrm{C}(1 \mathrm{~min}), 40^{\circ} \mathrm{C} \mathrm{min}^{-1}$ até $200^{\circ} \mathrm{C}(3 \mathrm{~min}), 50^{\circ} \mathrm{C} \mathrm{min}^{-1}$ até $230^{\circ} \mathrm{C}(0,5$ $\min )$.

\section{RESULTADOS E DISCUSSÃO}

\subsection{Evolução do pH e Produção de $\mathrm{H}_{2}$}

As condições de operação do reator, como o controle de $\mathrm{pH}$, são cruciais para o sucesso na produção biológica de $\mathrm{H}_{2}$. Na fase de partida do reator o afluente apresentou média de $\mathrm{pH}$ de 6,34, não havendo inicialmente a necessidade da adição de bicarbonato de sódio $\left(\mathrm{NaHCO}_{3}\right)$ como alcalinizante. Durantes os ensaios 1 e 2, o reator RAHLF apresentou dificuldade no controle de estabilidade do $\mathrm{pH}$, resultando médias de coeficientes de variação de até $18 \%$. Devido à natureza de seu fluxo pistonado, onde a faixa inicial não possui as mesmas características da região central e final, uma vez que o afluente vai sendo degradado ao longo do reator, fez com que a porção final tivesse uma maior quantidade de ácidos. A faixa de $\mathrm{pH}$ ideal para as bactérias acidogênicas é entre 5 e 6 [28]. Dessa forma, no Ensaio 1 foi adicionado $1 \mathrm{~g} \mathrm{~L}^{-1} \mathrm{de} \mathrm{NaHCO}_{3}$, o que resultou numa média de $\mathrm{pH}$ do afluente de $7,18( \pm 0,44)$.

A produção de $\mathrm{H}_{2}$ foi observada a partir do $89^{\circ}$ dia de operação na fase de partida do reator, com média diária de produção de $1,0 \mathrm{~mol} \mathrm{H}_{2} \mathrm{~m}^{3} \mathrm{~d}^{-1}( \pm 2,1)$ e média de $\mathrm{pH}$ de $4,48( \pm 0,73)$ (Figura 2). A eficiência do pré-tratamento do inóculo foi comprovada pela ausência de metano na composição do biogás, com gerações de somente $\mathrm{H}_{2}$ e $\mathrm{CO}_{2}$.

Com a alteração no TDH de $10 \mathrm{~h}$ para $24 \mathrm{~h}$, na fase de partida, foram observadas conversões mais elevadas de glicerol livre em $\mathrm{H}_{2}$ com produção diária de até $0,42 \mathrm{~mol} \mathrm{H}_{2} \mathrm{~mol}^{-1}$ glicerol. Tais eficiências foram superiores às verificadas por Vasconcelos et al. (2019) [29], em reator UASB com COV de 54,5 Kg DQO $\left(\mathrm{m}^{3}\right.$ d) ${ }^{-1}$ que foram de $0,096 \mathrm{~mol} \mathrm{H}_{2} \mathrm{~mol}^{-1}$ glicerol. Tais fatos indicaram que a microbiota pode apresentar dificuldades da conversão do glicerol para $\mathrm{H}_{2}$ em altas taxas orgânicas. Os reatores RAHLF se mostraram eficientes na conversão de $\mathrm{H}_{2}$, se aproximando até das maiores conversões de trabalhos que utilizaram culturas puras como Enterobacter aerogenes e atingiram conversões de 0,69 a 1,12 $\mathrm{mol} \mathrm{H}_{2} \mathrm{~mol}^{-1}$ glicerol em reatores anaeróbios em batelada $[\underline{30}, \underline{31}]$.

No Ensaio 2, com o aumento do percentual de glicerol bruto no afluente para $1,5 \%$, a quantidade de $\mathrm{NaHCO}_{3}$ no afluente foi elevada para $3 \mathrm{~g} \mathrm{~L}^{-1}$, conferindo uma média de $\mathrm{pH}$ de $7,47( \pm 0,28)$. A média de $\mathrm{pH}$ do efluente foi de 5,87 , porém com um desvio padrão de $\pm 1,08$. Essas variações do $\mathrm{pH}$ podem ter interferido diretamente no rendimento da produção de $\mathrm{H}_{2}$ durante o Ensaio 2. Em 24h de operação, utilizando apenas $1,5 \%$ de glicerol, sem outra fonte principal de matéria orgânica, foi verificada produção volumétrica diária de $1 \mathrm{~L}$ de $\mathrm{H}_{2} \mathrm{~L}^{-1}$. SILVA et al. [32] obtiveram produção de $\mathrm{H}_{2}$, mais elevada em reatores operados em batelada

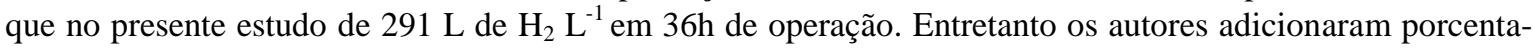
gens mais elevadas de glicerol $(3 \%)(\mathrm{v} / \mathrm{v})$ e os mesmos foram co-digeridos com resíduos de alimentos que possuem maior variabilidade nutricional do que o esgoto sanitário que foi usado no presente estudo. Ou seja; para melhoria da conversão do glicerol bruto $\mathrm{em}_{2}$, outros resíduos orgânicos adicionados ao afluente poderiam ser aplicados, como solução para a utilização de maiores percentuais de glicerol nas próximas fases de operação.

Os picos máximos de produção de hidrogênio registrados foram excelentes resultados, corroborando a potencialidade inexplorada de produção de $\mathrm{H}_{2}$ em RAHLF com alimentação contínua. O ponto de maior geração ocorreu no ensaio 2, onde foram verificadas gerações de 11,34 mols de $\mathrm{H}_{2} \mathrm{por} \mathrm{m}^{3}$ de reator $\mathrm{d}^{-1}$. Durante a partida e Ensaio 1 as gerações mais elevadas de produção foram 8,41 e 10,32 mols $\mathrm{H}_{2} \mathrm{~m}^{3} \mathrm{~d}^{-1}$, respectivamente (Figura 2).

A média de produção foi de 1,8 mols de $\mathrm{H}_{2}$ por $\mathrm{m}^{3} \mathrm{~d}^{-1}( \pm 2,2)$ no ensaio 2. Além disso, a média de $\mathrm{pH}$ 
neste ensaio foi de 5,87 $( \pm 1,08)$ com um coeficiente de variação de $18 \%$. A instabilidade no pH pode ter contribuído para a diminuição na produção de hidrogênio, onde por vários períodos o efluente do reator não se manteve na faixa ótima para a microbiota do reator. Diversos trabalhos buscam a resposta para qual seria a faixa de pH mais adequada para se atingir maiores produções de $\mathrm{H}_{2}$, porém além de fatores como constituição do substrato que compõe seu afluente, é muito importante estudar quais são os microrganismos que compõem o lodo do reator. MIRZOIAN et al. [33] comprovou isto ao comparar uma espécie de Escherichia coli selvagem (BW25113) e uma mutante (JW0955), na co-digestão anaeróbia de glicerol (10 g L $\left.{ }^{-1}\right)$ com lactose $\left(1 \mathrm{~g} \mathrm{~L}^{-1}\right)$; onde a espécie selvagem atingiu sua maior produção de $20 \mathrm{mmols}_{2} \mathrm{~L}^{-1}$ em faixa de $\mathrm{pH} 7,5-8 \mathrm{e}$, com a espécie mutante foram verificadas produções de 9 mmols $\mathrm{H}_{2} \mathrm{~L}^{-1}$, em $\mathrm{pH}$ 6,5. Isso comprova a necessidade de se adequar a faixa de $\mathrm{pH}$ ideal para cada tipo de inoculo e fonte de matéria orgânica.

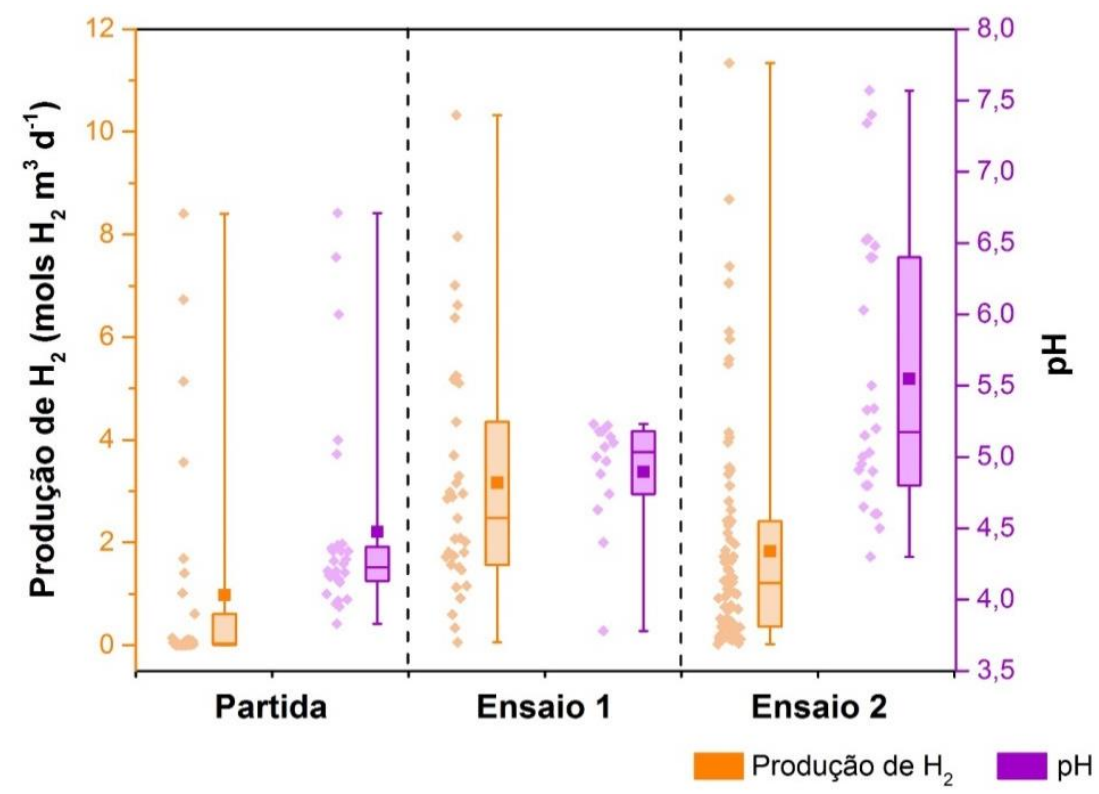

Figura 2: Produção de Hidrogênio e variação no pH do efluente do reator RHALF nas fases de: Partida, Ensaio 1 e Ensaio 2 .

\subsection{Produção de Ácidos Graxos Voláteis (AGV)}

Os AGV são gerados na digestão anaeróbia, durante a etapa de acidogênese, acetogênese sintrófica e homoacetogênese [34]. As médias de AGV totais na partida, Ensaio 1 e Ensaio 2 foram, respectivamente, de 386 ( \pm 405), 289 ( \pm 181$)$ e $353( \pm 195) \mathrm{mg} \mathrm{L}^{-1}$. Tais resultados evidenciaram que não houve inibição nas gerações de AGV no reator (Figura 3). O acondicionamento do afluente a $4^{\circ} \mathrm{C}$, durante os Ensaios 1 e 2, ajudaram evitar a sua acidificação prévia, o que conferiu valores mais estáveis de $\mathrm{AGV}$, quando comparados à fase de partida onde o afluente foi mantido em temperatura ambiente.

Obteve-se a maior média de produção de $\mathrm{AGV}$ de $3,4 \mathrm{~g} \mathrm{~L}^{-1}( \pm 1,4)$, durante o ensaio 2 Concentrações de AGV elevadas no reator podem inibir a atividade microbiana e levar o sistema à falência. Na co-digestão de glicerol bruto com agua residuária de suinocultura, He et al. [35] ao atingirem a proporção de $8 \%$ de glicerol (v/v), constataram a falência do reator devido ao acumulo de $\mathrm{AGV}\left(4,2 \mathrm{~g} \mathrm{~L}^{-1}\right)$. A suplementação de alcalinidade com a adição de $\mathrm{NaHCO}_{3}$ durante os ensaios 1 e 2 foram essenciais para evitar a inibição do processo fermentativo. 


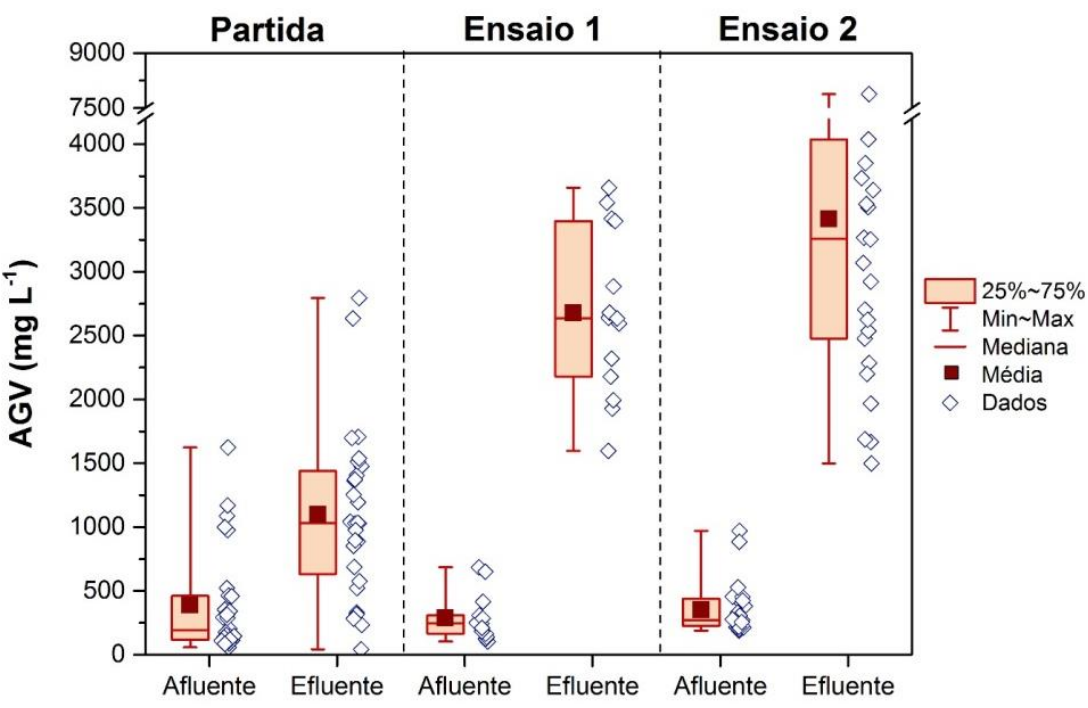

Figura 3: Produção de Ácidos Graxos Voláteis (AGV) no Afluente e Efluente do RAHLF

$\mathrm{O} \mathrm{pH}$ é um fator crucial na produção de AGV. Determinadas faixas de $\mathrm{pH}$ podem influenciar não só na quantidade de ácido total produzido, como também sua variabilidade [36]. Na fermentação da glicose em reatores operados em batelada, ATASOY et al. [36] estudando diferentes $\mathrm{pH}$ (5, 8 e 10), obteve uma melhor produção de $\mathrm{AGV}$ em pH 10, devido a capacidade de tamponamento que esta condição forneceu. Entretanto, os autores verificaram, para reatores operados continuamente em $\mathrm{pH}$ neutro $(7,0)$ a melhor opção para favorecer microrganismos fermentativos na produção de AGV. Porém, para produção de $\mathrm{H}_{2} \mathrm{e}$ evitar a atividade das arquéias metanogênicas consumidoras de hidrogênio, $\mathrm{pH}$ mais ácidos $(5,5)$ são mais eficazes para produção de $\mathrm{H}_{2}$ [37].

Os ácidos e álcoois resultantes do metabolismo das bactérias fermentativas podem ser utilizados como substrato para a produção de $\mathrm{H}_{2}$, graças a bactérias como Rhodopseudomonas spp. que possuem afinidade por AGV e o utilizam como substrato [38]. TAO et al. [39] isolaram e identificaram uma espécie de bactéria fotossintética (PNSB, ZX-5), capaz de proporcionar conversões de AGV até 71,5\% de $\mathrm{H}_{2}$. Os AGV possuem valor agregado, podendo não somente ser utilizados como fonte de carbono para produção de $\mathrm{CH}_{4}$ em reatores metanogênicos, mas também serem explorados para maiores produções de $\mathrm{H}_{2}$.

\subsection{Análise microbiológica}

O lodo in natura apresentou diversidade, com crescimento de colônias em todos os meios específicos utilizados (Figura 4). Entretanto, na quantificação destes microrganismos foram observadas alterações no inóculo e após o ensaio 1.

No inoculo in natura foram verificadas contagens mais elevadas de colônias para Bacteroides sp. $\left(5,4 \times 10^{4}\right.$ UFC $\left.\mathrm{mL}^{-1}\right)$, seguido por Veillonella sp. $\left(2,0 \times 10^{4} \mathrm{UFC} \mathrm{mL}^{-1}\right)$; ambos reconhecidos como bactérias fermentativas, gram negativas, não formadoras de esporos, envolvidas principalmente na conversão de propionato [40] e de Hidrogênio [41]. Após 260 dias de operação do reator, ao final do Ensaio 1, houve aumento

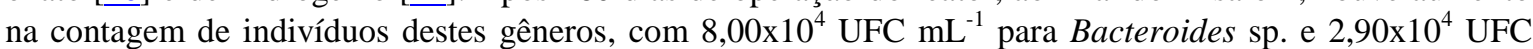
$\mathrm{mL}^{-1}$ para Veillonella sp. Na fermentação de sacarose, SONG et al. [25] observaram o mesmo comportamento do presente estudo para Veillonella sp. depois do $5^{\circ}$ dia de fermentação, que elevou de $1,1 \times 10^{5} \mathrm{UFC} \mathrm{mL}^{-1}$ para $8,0 \times 10^{6} \mathrm{UFC} \mathrm{mL}^{-1}$. Semelhantemente foi verificado em contagens elevadas do gênero Bacteroides sp. de $7,7 \times 10^{5} \mathrm{UFC} \mathrm{mL} \mathrm{m}^{-1}$.

No inoculo in natura utilizado neste trabalho Bacteroides sp. e Veillonella sp. representaram, respectivamente $58 \%$ e $22 \%$ da população de bactérias quantificadas no inoculo. Entretanto, ao final do Ensaio 1 foi verificado $36 \%$ de bacteroides sp. e 13\% de Veillonella sp. mostrando que o pré-tratamento ácido do inoculo aliado à condição operacional do reator, principalmente com adições de glicerol bruto, contribuíram para a alteração desses gêneros, além de propiciar condições adequadas para o estabelecimento de outros.

Foram verificados no inoculo in natura 7,0x $10^{3} \mathrm{UFC} \mathrm{mL}^{-1}$ de Clostridium sp., apresentando aumento para $3,4 \times 10^{4} \mathrm{UFC} \mathrm{mL}^{-1}$ no Ensaio 1. Os indivíduos desta ordem obtiveram aumento não apenas em número, mas também em relação a população microbiana, onde no inóculo representavam 8\%, e ao final do Ensaio 1 
já perfaziam 15\%. O gênero Clostridium possui morfologias de bacilos Gram+ formadores de endósporos e reconhecidos como produtores de hidrogênio [42], são também geradores de outros metabólitos de valor agregado, como o 1,3-propanodiol [43], o que pode favorecer sua adaptação no reator alimentado com glicerol bruto [37].

Com exceção do gênero Enterobacter sp., os demais microrganismos apresentam crescimento ao final do Ensaio 1, como Streptococcus sp., e Lactobacillus sp., que são microrganismos anaeróbios, comumente observados durante a operação de reatores anaeróbios geradores de Hidrogênio [25]. É importante destacar a elevada quantidade de Lactobacillus sp. na população microbiana onde foram verificados $3 \%$ ( $7,0 \mathrm{X} 10^{3} \mathrm{UFC}$ $\left.\mathrm{mL}^{1}\right) 24 \%\left(5,5 \times 10^{4} \mathrm{UFC} \mathrm{ml}^{-1}\right)$ no inoculo in natura. Bactérias láticas do gênero Lactobacillus, são em sua maioria conhecidas como maléficas à produção de $\mathrm{H}_{2}$. Entretanto, tais microrganismos suportam elevadas cargas orgânicas, como no presente estudo, além de serem produtores de biocinas, capazes de inibir outros microrganismos produtores de $\mathrm{H}_{2}[\underline{44}, \underline{45}]$. $\mathrm{O}$ aumento desta população pode ter prejudicado o alcance de melhores índices de produção no Ensaio 2, com o aumento do percentual de glicerol e consequente elevação da carga orgânica no efluente para 1,5\%, que pode ter favorecido outras rotas metabólicas contrárias a produção de $\mathrm{H}_{2}$. As espécies Lactobacillus brevis [46], Lactobacillus diolivorans [47] e Lactobacillus panis [48] já são relatadas como produtoras de 1,3-propanodiol a partir de glicerol.

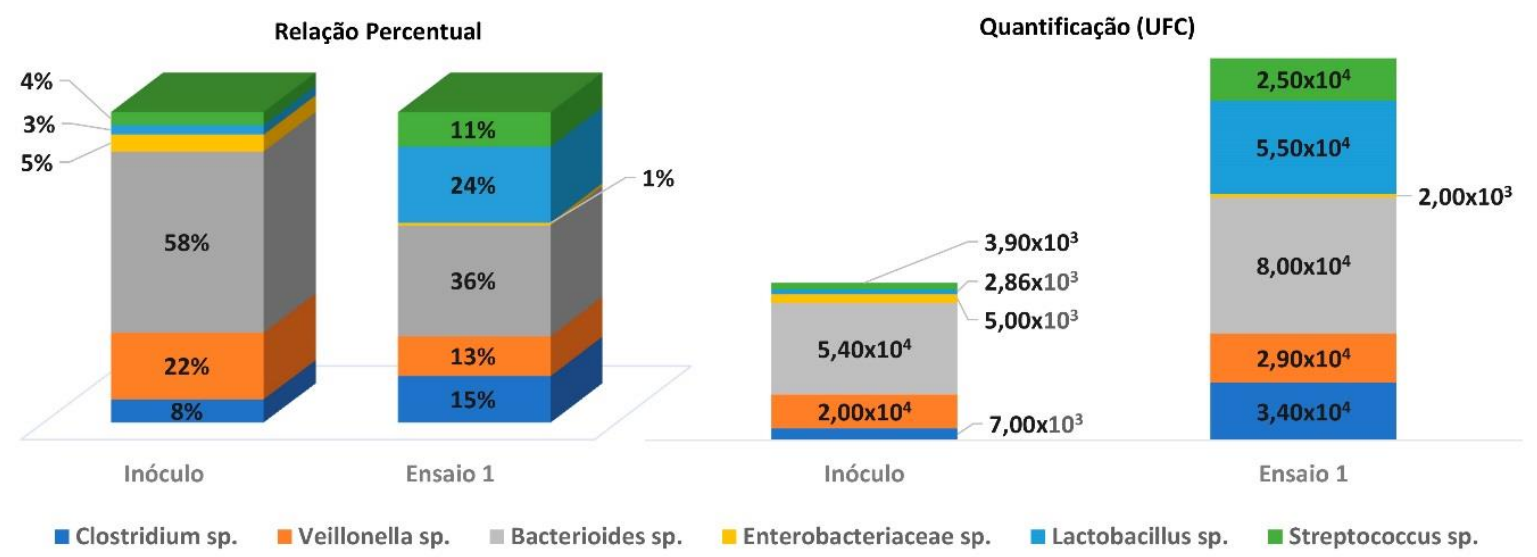

Figura 4: Quantificação de bactérias anaeróbias por técnica de pour plate em Unidades Formadoras de Colônias (UFC) no inóculo in natura (Inóculo) e pré-tratado (Ensaio 1)

\section{CONCLUSÕES}

A co-digestão com esgoto sanitário foi eficiente para diluição da elevada carga orgânica do glicerol bruto, e seus contaminantes, evitando a inibição da microbiota por falência dos reatores.

$\mathrm{O}$ pré-tratamento no lodo inativou os microrganismos metanogênicos, com geração de apenas $\mathrm{H}_{2} \mathrm{e} \mathrm{CO}_{2}$ na composição do biogás.

O reator RAHLF atingiu excelentes picos de produção de $\mathrm{H}_{2}$ de até 11,34 mols de $\mathrm{H}_{2}$ por $\mathrm{m}^{3}$ de reator $\mathrm{d}^{-}$ ${ }^{1}$, mostrando a viabilidade de aplicação de reatores contínuos, porem para sua estabilidade, melhorias como o controle de $\mathrm{pH}$ e suplementação de alcalinizante precisam ser melhor implementadas.

A quantificação de bactérias indicou que outras rotas metabólicas podem estar sendo favorecidas, onde não há apenas produção de $\mathrm{H}_{2}$ como também outros compostos como 1,2-propanodiol.

\section{AGRADECIMENTOS}

À Capes pelo suporte da bolsa de doutorado.

À FAPESP (Proc 2017/16795-3) pelo suporte na manutenção das análises laboratoriais.

Ao Laboratório didático do curso de Engenharia Química do IQ Unesp Araraquara pelo apoio na construção do reator. 


\section{BIBLIOGRAFIA}

[1] BiodieselBR, “Usinas de Biodiesel no Brasil," 2017. [Online]. Available: http://www.biodieselbr.com/usinas/. [Accessed: 20-May-2017].

[2] MAINTINGUER, S.I., HATANAKA, R.R., OLIVEIRA, J.E. "Glycerol as a Raw Material for Hydrogen Production," in Biofuels - Status and Perspective, n. November 2014, InTech, 2015, p. 580.

[3] RIVERO, M., SOLERA, R., PEREZ, M. "Anaerobic mesophilic co-digestion of sewage sludge with glycerol: Enhanced biohydrogen production,” doi: 10.1016/j.ijhydene.2013.12.006. Int. J. Hydrogen Energy, v. 39, n. 6, pp. 2481-2488, 2014.

[4] PACHAURI, N., HE, B. "Value-added Utilization of Crude Glycerol from Biodiesel Production : A Survey of Current Research Activities,” doi: 10.1080/15422119.2013.851696. Am. Soc. Agric. Biol. Eng., v. 0300, n. 06, pp. 1-16, 2006.

[5] FAO (Food and Agriculture Organization), “OECD-FAO Agricultural Outlook,” Paris, 2015.

[6] SILVA, G.P., MACK, M., CONTIERO, J. "Glycerol: A promising and abundant carbon source for industrial microbiology," doi: 10.1016/j.biotechadv.2008.07.006. Biotechnol. Adv., v. 27, n. 1, pp. 30-39, 2009.

[7] HÁJEK, M., SKOPAL, F. “Treatment of glycerol phase formed by biodiesel production," doi: 10.1016/j.biortech.2009.12.094. Bioresour. Technol., v. 101, n. 9, pp. 3242-3245, 2010.

[8] RAHMAT, N., ABDULLAH, A.Z., MOHAMED, A.R. "Recent progress on innovative and potential technologies for glycerol transformation into fuel additives: A critical review," doi:

10.1016/j.rser.2009.11.010. Renew. Sustain. Energy Rev., v. 14, n. 3, pp. 987-1000, 2010.

[9] SANTANA, K.O., RODRIGUES, C.V., NESPECA, M.G., et al., "Hydrogen bioprodution from crude glycerol and wastewater," Ciência Tecnol. Fatec-JB, v. 8, pp. 1-14, 2016.

[10] COSTA, J.C., OLIVEIRA, J.V., ALVES, M.M. "Biochemical Methane Potential of Brewery Wastes and Co- Digestion With Glycerol,” 2nd Int. Conf., no. Cd, pp. 221-226, 2013.

[11] ATHANASOULIA, E., MELIDIS, P., AIVASIDIS, A. "Co-digestion of sewage sludge and crude glycerol from biodiesel production," doi: 10.1016/j.renene.2013.06.040. Renew. Energy, v. 62, n. PA, pp. 73-78, Feb. 2014.

[12] FOUNTOULAKIS, M.S., MANIOS, T. "Enhanced methane and hydrogen production from municipal solid waste and agro-industrial by-products co-digested with crude glycerol," doi: 10.1016/j.biortech.2009.01.016. Bioresour. Technol., vol. 100, no. 12, pp. 3043-3047, 2009.

[13] XIE, S., LAWLOR, P.G., FROST, J.P., et al., "Effect of pig manure to grass silage ratio on methane production in batch anaerobic co-digestion of concentrated pig manure and grass silage," doi: 10.1016/j.biortech.2011.03.009. Bioresour. Technol., v. 102, n. 10, pp. 5728-5733, 2011.

[14] WU, W. "Anaerobic co-digestion of biomass for methane production: recent research achievements," Optimization, pp. 1-10, 2007.

[15] PEDROZA, M., VIEIRA, G., SOUSA, J., et al., "Produção e tratamento de lodo de esgoto-uma revisão," Rev. Lib., v. 11, n. 16, pp. 89-188, 2010.

[16] Instituto Trata Brasil, "Saneamento no Brasil," 2019. [Online]. Available: http://www.tratabrasil.org.br/saneamento/principais-estatisticas/no-brasil/esgoto. [Accessed: 20-Jan-2020].

[17] ABREU, M., ZAIAT, S.B. "Desempenho de reator anaeróbio-aeróbio de leito fixo no tratamento de esgoto sanitário," Eng. Sanit. Ambient., v. 13, n. 2, 2008.

[18] ZHAI, N., et al., "Effect of initial pH on anaerobic co-digestion of kitchen waste and cow manure," doi: 10.1016/j.wasman.2014.12.027.Waste Manag., v. 38, pp. 126-131, 2015.

[19] SITTIJUNDA, S., REUNGSANG, A. "Valorization of crude glycerol into hydrogen, 1,3-propanediol, and ethanol in an up-flow anaerobic sludge blanket (UASB) reactor under thermophilic conditions," doi: 10.1016/j.renene.2020.07.053. Renew. Energy, v. 161, pp. 361-372, 2020.

[20] MAZARELI, R.C.S., DUDA, R.M., LEITE, V.D., et al., "Anaerobic co-digestion of vegetable waste and swine wastewater in high-rate horizontal reactors with fixed bed," doi: 10.1016/j.wasman.2016.03.021. Waste Manag., v. 52, pp. 112-121, 2016.

[21] ROSSI, D.M., COSTA, J.B., SOUZA, E.A., et al., "Comparison of different pretreatment methods for hydrogen production using environmental microbial consortia on residual glycerol from biodiesel," doi: 10.1016/j.ijhydene.2011.01.005. Int. J. Hydrogen Energy, v. 36, n. 8, pp. 4814-4819, 2011. 
[22] APHA, AWWA, WEF, Standard Methods for the Examination of Water and Wastewater, 21st ed. Washington DC, USA.: American Public Health Association, 2005.

[23] JENKINS, S.R., MORGAN, J.M., SAWYER, C.L. "Measuring anaerobic sludge digestion and growth by a simple alkalimetric titration," J. Water Pollut., v. 55, n. 5, pp. 448-453, 1983.

[24] DILALLO, R., ALBERTSON, O.E. "Volatile acids by direct titration," J. Water Pollut., v. 33, n. 4, p. $356,1961$.

[25] SONG, Z.X., DAI, Y., FAN, Q.L., et al. "Effects of pretreatment method of natural bacteria source on microbial community and bio-hydrogen production by dark fermentation," doi:

10.1016/j.ijhydene.2012.01.010. Int. J. Hydrogen Energy, v. 37, n. 7, pp. 5631-5636, 2012.

[26] ZUO, X., et al., "The relationships among sCOD, VFAs, microbial community, and biogas production during anaerobic digestion of rice straw pretreated with ammonia," doi: 10.1016/j.cjche.2019.07.015. Chinese J. Chem. Eng., n. xxxx, pp. 1-7, 2019.

[27] NETO, J.G., et al., "Quantificação de biogás em reatores anaeróbios através do método de deslocamento de volume de água," Rev. Estud. Ambient., v. 16, n. 1, pp. 45-53, 2014.

[28] SEIFERT, K., WALIGORSKA, M., WOJTOWSKI, M., et al., "Hydrogen generation from glycerol in batch fermentation process," doi: 10.1016/j.ijhydene.2009.02.045. Int. J. Hydrogen Energy, v. 34, n. 9, pp. 3671-3678, 2009.

[29] VASCONCELOS, E.A.F., SANTAELLA, S.T., VIANA, M.B., et al., "Composition and ecology of bacterial and archaeal communities in anaerobic reactor fed with residual glycerol," doi:

10.1016/j.anaerobe.2019.06.014. Anaerobe, v. 59, pp. 145-153, 2019.

[30] SELEMBO, P.A., PEREZ, J.M., LLOYD, W.A., et al., "Enhanced hydrogen and 1,3-propanediol production from glycerol by fermentation using mixed cultures," doi: 10.1002/bit.22487. Biotechnol. Bioeng., v. 104, n. 6, pp. 1098-1106, 2009.

[31] NGO, T.A., KIM, M.S., SIM, S.J. "High-yield biohydrogen production from biodiesel manufacturing waste by Thermotoga neapolitana," doi: 10.1016/j.ijhydene.2010.11.057. Int. J. Hydrogen Energy, v. 36, n. 10, pp. 5836-5842, 2011.

[32] SILVA, F.M.S., OLIVEIRA, L.B., MAHLER, C.F., et al., "Hydrogen production through anaerobic codigestion of food waste and crude glycerol at mesophilic conditions," doi: 10.1016/j.ijhydene.2017.07.159. Int. J. Hydrogen Energy, v. 42, n. 36, pp. 22720-22729, 2017.

[33] MIRZOYAN, S., TRCHOUNIAN, A., TRCHOUNIAN, K. "Hydrogen production by Escherichia coli during anaerobic utilization of mixture of lactose and glycerol: Enhanced rate and yield, prolonged production,” doi: 10.1016/j.ijhydene.2019.02.114. Int. J. Hydrogen Energy, v. 44, n. 18, pp. 9272-9281, 2019.

[34] AMANI, T., NOSRATI, M., SREEKRISHNAN, T.R. "Anaerobic digestion from the viewpoint of microbiological, chemical, and operational aspects - A review," doi: 10.1139/A10-011. Environ. Rev., v. 18, n. 1, pp. 255-278, 2010,

[35] FIERRO, J., MARTINEZ, E.J., ROSAS, J.G., et al., "Co-Digestion of Swine Manure and Crude Glycerine: Increasing Glycerine Ratio Results in Preferential Degradation of Labile Compounds," doi: 10.1007/s11270-016-2773-7. Water. Air. Soil Pollut., v. 227, n. 3, 2016.

[36] ATASOY, M., EYICE, O., SCHNÜRER, A., et al., "Volatile fatty acids production via mixed culture fermentation: Revealing the link between $\mathrm{pH}$, inoculum type and bacterial composition," doi: 10.1016/j.biortech.2019.121889. Bioresour. Technol., v. 292, n. July, p. 121889, 201.

[37] RODRIGUES, C.V., NESPECA, M.G., SAKAMOTO, I.K., et al., "Bioconversion of crude glycerol from waste cooking oils into hydrogen by sub-tropical mixed and pure cultures," doi: 10.1016/j.ijhydene.2018.02.174. Int. J. Hydrogen Energy, pp. 144-154, 2019.

[38] STRAZZERA, G., BATTISTA, F., GARCIA, N.H., et al., "Volatile fatty acids production from food wastes for biorefinery platforms: A review," doi: 10.1016/j.jenvman.2018.08.039. J. Environ. Manage., v. 226, no. August, pp. 278-288, 2018.

[39] TAO, Y., et al., "Characteristics of a new photosynthetic bacterial strain for hydrogen production and its application in wastewater treatment," doi: 10.1016/j.ijhydene.2007.11.021. Int. J. Hydrogen Energy, v. 33, n. 3, pp. 963-973, 2008.

[40] GERARDI, M.H. The Microbiology of Anaerobic Digesters. Hoboken, NJ, USA: John Wiley \& Sons, Inc., 2003. 
[41] PACHIEGA, R., SAKAMOTO, I.K., VARESCHE, M.B., et al. "Obtaining and Characterization of Mesophilic Bacterial Consortia from Tropical Sludges Applied on Biohydrogen Production,” doi: 10.1007/s12649-017-0185-6. Waste and Biomass Valorization, 2018.

[42] CITELLI, I.R., PIRES, L.O., MAINTINGUER, S.I., et al., “Avaliação da geração de metano por biomassa anaeróbia utilizando glicerol bruto como substrato Resultados e Discussão Material e Métodos,” p. $2011,2011$.

[43] JITRWUNG, R., VERRETT, J., YARGEAU, V. “Optimization of selected salts concentration for improved biohydrogen production from biodiesel-based glycerol using Enterobacter aerogenes," doi: 10.1016/j.renene.2012.06.049. Renew. Energy, v. 50, n. 3, pp. 222-226, 2013.

[44] GOMES, B.C., ROSA, P.R.F., ETCHEBEHERE, C., et al., "Role of homo-and heterofermentative lactic acid bacteria on hydrogen-producing reactors operated with cheese whey wastewater," doi: 10.1016/j.ijhydene.2015.05.035. Int. J. Hydrogen Energy, v. 40, n. 28, pp. 8650-8660, 2015.

[45] ROSA, P.R.F., GOMES, B.C., VARESCHE, M.B.A., et al. "Characterization and antimicrobial activity of lactic acid bacteria from fermentative bioreactors during hydrogen production using cassava processing wastewater,” doi: 10.1016/j.cej.2015.08.088. Chem. Eng. J., v. 284, pp. 1-9, 2016.

[46] VIVEK, N., PANDEY, A., BINOD, P. "Biological valorization of pure and crude glycerol into 1,3propanediol using a novel isolate Lactobacillus brevis N1E9.3.3," doi: 10.1016/j.biortech.2016.02.020. Bioresour. Technol., v. 213, pp. 222-230, 2016.

[47] PFLÜGL, S., MARX, H., MATTANOVICH, D., et al., "Heading for an economic industrial upgrading of crude glycerol from biodiesel production to 1,3-propanediol by Lactobacillus diolivorans,", doi: 10.1016/j.biortech.2013.11.041. Bioresour. Technol., v. 152, pp. 499-504, 2014.

[48] GRAHAME, D.A.S., KANG, T.S., KHAN, N.H., et al., "Alkaline conditions stimulate the production of 1,3-propanediol in Lactobacillus panis PM1 through shifting metabolic pathways," doi: 10.1007/s11274013-1283-7. World J. Microbiol. Biotechnol., v. 29, n. 7, pp. 1207-1215, 2013.

\section{ORCID}

Luan Vieira Adames

Lorena Oliveira Pires

Maria Ângela Tallarico Adorno

Sandra Imaculada Maintinguer
https://orcid.org/0000-0002-3912-687X

https://orcid.org/0000-0002-1447-259X

https://orcid.org/0000-0002-5340-889X

https://orcid.org/0000-0002-4584-7649 